\title{
PROBLEMS WITH SLEEP DO NOT PREDICT SELF-REPORTED DRIVING FACTORS AND PERCEPTION IN OLDER DRIVERS: EVIDENCES FROM THE CANDRIVE II PROSPECTIVE COHORT
}

\author{
Sylvain Gagnon ${ }^{1}$, Andrea J. Hickey ${ }^{1}$, Kelly Weegar ${ }^{2}$, Yara Kadulina ${ }^{1}$, Shawn Marshall ${ }^{2}$, Anita \\ Myers $^{3}$, Holly Tuokko ${ }^{4} \&$ Michel Bédard ${ }^{5}$ for the Candrive Research Team \\ ${ }^{1}$ University of Ottawa, Ontario, Canada \\ ${ }^{2}$ Ottawa Hospital Research Institute, Ottawa, Ontario, Canada \\ ${ }^{3}$ University of Waterloo, Waterloo, Ontario, Canada \\ ${ }^{4}$ Centre for Aging, Victoria, British Columbia, Canada \\ ${ }^{5}$ Centre for Research on Safe Driving, Lakehead University, Canada \\ Email:sgagnon@uottawa.ca
}

\begin{abstract}
Summary: Given that sleep problems and serious motor vehicle collisions are increasingly prevalent in older adults, even minor drowsiness could potentially contribute to driving patterns in older drivers. To date, it is unknown whether less serious problems with sleep influence driving frequency and ability in older adults. We investigated the influence of everyday sleep disturbances on driving practices and driver perceptions in a large cohort of healthy older drivers. Selfreported measures of sleep problems were used to investigate the influence of sleep disturbance on self-reported driving practices and perceived driving abilities. On two measures of self-reported driving outcomes, participants with problems with rated themselves more poorly. However, this relationship disappeared when health and demographic variables were entered prior in hierarchical regression analyses. Our results show that the relationship between sleep problems, driving frequency and perceived abilities is better explained by mediating demographic, health, and cognitive factors.
\end{abstract}

\section{INTRODUCTION}

Approximately 20 to 50\% of older adults report having sleep problems (Chen et al., 2011; Lopez-Torres Hidalgo et al., 2011; Vitiello, 1997), compared to roughly 5 to $30 \%$ in the general population (Bjorngaard et al., 2011; Ohayon, 2002). In an epidemiological study of 9,000 participants aged 65 and older, the National Institute on Aging found that over half of older adults reported at least one of these complaints as occurring most of the time-trouble falling asleep, waking up, awaking too early, needing to nap and not feeling rested (Foley et al., 1995). It is generally argued that the increase in concurrent medical conditions can produce greater sleep disruption with age, such that sleep complaints common in older adults are often secondary to their comorbidities (Foley et al., 2004).

Despite the awareness of the risks involved, polls of drivers conducted worldwide find that many drivers admit to driving drowsy (Sleep in America poll. 2012; Sagaspe et al., 2010; Vanlaar et al., 2008), and older drivers seem to be no different than the other cohorts of drivers. Vaz Fragoso and colleagues found that a large percentage continued to drive regularly despite reporting dissatisfaction with their sleep (Vaz Fragoso et al., 2008). The important question that 
remains is whether sleep problems can partly explain changes in driving behaviors seen in older adults.

Most of the research to date on sleep and driving in older adults has focused on sleep disorders, such as obstructive sleep apnea, or other clinically significant sleep problems as indicated by various objective sleep measures (e.g., the Sleep Impairment Index). Nevertheless, the presence of less serious sleep disturbances may still influence driving patterns in older drivers. To our knowledge, the impact of less severe sleep problems on driving in older adults has yet to be fully circumscribed. Indeed, findings remain mixed regarding whether perceived sleepiness is associated with crash risk and impaired driving performance in older drivers (Ellen et al., 2006). For instance, Vaz Fragoso et al (2008) found that older drivers with sleep problems rated their driving ability more poorly, especially concerning night driving. They also found that these individuals had more health issues in general but did not examine whether these issues may have influenced the relationship between sleep problems and self-rated driving. The present study sought to investigate the independent influence of everyday sleep problems on self-reported driving practices and perceived driving abilities in a large cohort of healthy older drivers. Specifically, we examined the contribution of self-reported sleep problems, while controlling for medical conditions, cognitive function, age and of driver characteristics. We hypothesized that even mild sleep problems would be associated with self-reported driving restrictions and poorer driver perceptions of their abilities.

\section{METHOD}

\section{Participants}

Participants from the Candrive II prospective cohort study were investigated. Candrive II is a Canadian Institutes of Health Research (CIHR)-funded interdisciplinary research team interested in health-related safety and quality-of-life issues pertinent to active older drivers (Marshall et al., 2012). Participants $(\mathrm{N}=928$, aged 70 or older) were recruited largely through media from seven Canadian cities in four provinces including Toronto, ON, Ottawa, ON, Hamilton, ON, Thunder Bay, ON, Montreal, QC, Winnipeg, MB and Victoria, BC.

\section{Procedures}

All participants underwent a comprehensive baseline assessment by trained research staff, which incorporated a variety of measures that can be easily administered in a primary care clinic setting). The assessment included measures of sensory, physical and cognitive functioning, and information about psychosocial factors, health status, and driving habits and behaviors. The baseline assessment required approximately 2.5 to 4 hours to complete. The following analyses pertaining to the present study will only be applied to a subset of the variables collected at baseline.

\section{Measures of interest}

Problems with sleep. All participants were asked “Do you have any sleep problems?” with a dichotomous response, yes or no. Although the self-reported declaration of sleep problems is 
arguably subjective, previous researchers indicate that self-perception of fatigue in older individuals may be a better predictor of performance decrement over time than objectively measured sleepiness (Philip et al., 2004).

Self-reported driving outcomes. Driving practices were assessed using the Situational Driving Frequency (SDF) and Avoidance (SDA) scales (MacDonald, Myers \& Blanchard, 2008). On the SDF, participants are asked how often they drive, on average, in 14 different driving. On the SDA, people are asked "If possible, do you try and avoid any of these driving situations?", "check all that apply" on a list of 20 situations (e.g., night, dawn or dusk, bad weather conditions in general, etc.) Both scales were developed inductively with older drivers and have shown good internal consistency and test-retest reliability (MacDonald et al., 2008; Blanchard \& Myers, 2010). Driver perceptions were assessed using the 15-item Perceived Driving Abilities (PDA) scale, which asks participants to rate various aspects of their abilities (e.g., see road signs at night, make quick driving decisions, etc.) on a 4-point scale (from $0=$ poor to $3=$ very good).

Control variables. Demographic (age, gender) and health information (self-reported chronic conditions referred below as number of medical conditions, Body Mass Index [BMI], depression and medication list) were included to describe their mediating effect in the statistical analysis models. The inclusion of the above variables is justified by the known influence of one's lifestyle and health-related factors on sleep as well as on driving (e.g., Verster et al., 2004; Barrash et al., 2010; Leproust et al., 2008). Participants’ cognitive functioning scores (MoCA) were also included as a control.

\section{RESULTS}

Table 1 presents demographics, health, medication use, mood, and cognitive functioning between older drivers with self-reported sleep problems $(N=194)$ and those without $(N=668)$. The two groups had similar BMI scores, MoCA scores, and were of similar age. The comparison of anticholinergic use between those with no sleep problems and those with sleep problems was significant, (1.0 vs. $\left.3.1 \%, \chi^{2}=4.31, p=0.05\right)$. A larger proportion of older drivers without sleep problems were male $\left(63.6 \%\right.$ versus $36.4 \%$ of females; $\left.\chi^{2}=11.49, p<0.05\right)$, whereas the gender frequencies of older drivers with sleep problems were evenly distributed (50.0\% male, 50.0\% female; $\left.\chi^{2}=10.57, p>0.05\right)$. Table 1 also shows that, on average, older drivers without sleep problems had significantly fewer chronic medical conditions $(M(S D)=7.0(3.32)$ versus 8.5(3.64), $t(834)=5.52, p<0.05)$, were significantly more likely to be using benzodiazepines (6.4\% versus $\left.20.3 \%, \chi^{2}=33.20, p<0.05\right)$, and to have depression scores greater than $5(1.3 \%$ versus $\left.4.2 \%, \chi^{2}=6.10, p<0.05\right)$. Participants with self-reported sleep problems also scored significantly lower on the SDF, $t(844)=2.90, p<.01$; and PDA $t(846)=4.26, p<.01$ scales compared to those without self-reported sleep problems. No significant difference between groups was found for the SDA. In order to assess whether the observed differences remain after controlling for demographic and health related variables, hierarchical regressions analyses were conducted for each one of the driving variables.

Hierarchical regressions were run independently on all three scales. In each analysis, the control variables were entered first. For SDF, control variables explained $13 \%$ of the variance when entered at step 1. For SDA, the contribution of the same variables was $8 \%$ at Step 1 . In both 
cases, entering sleep problems at step 2 had absolutely no effect on the model. For PDA, control variables explained 7\% of the variance at step 1 and the inclusion of sleep problems at Step 2 was significant but contributed for only $1 \%$ of the variance.

\section{DISCUSSION}

This study examined the relationship between self-reported sleep problems and driving practices and driver perceptions in a large cohort of older drivers. Group comparisons between those who reported having problems with sleep and those who did not revealed a significant difference on SDF and PDA. Older drivers with sleep problems reported lower driving frequency and lower self-perceived ability in comparison to older drivers who did not report problems with sleep. After controlling for a number of variables that could potentially influence the relationship between sleep and driving (age, gender, BMI, cognitive functioning, number of current medical conditions, medication use, and depression), self-reported sleep problems did not predict SDF nor SDA, and only explained $1 \%$ of the variance on PDA. These results demonstrate that everyday sleep problems or lack thereof does not significantly influence self-reported driving patterns or perceived driving abilities in older drivers. Our findings demonstrate that subclinical sleep problems have little to no influence on driving practices and abilities as reported by the older driver.

Table 1. Demographics, health, and cognitive functioning of older drivers with/without sleep problems based on self-reporting (yes/no)

\begin{tabular}{|c|c|c|c|c|c|c|c|c|}
\hline & $\begin{array}{l}\text { No S } \\
\text { (Self }\end{array}$ & $\begin{array}{l}\text { ep Problems } \\
\text { eported) } \\
\text { Participant }\end{array}$ & & $\begin{array}{l}\text { Slee } \\
\text { (Self }\end{array}$ & $\begin{array}{l}\text { Problems } \\
\text { eported) } \\
\text { Participant }\end{array}$ & & & \\
\hline Characteristics & $\mathrm{N}$ & $\mathrm{N}(\%)$ & $M(\mathrm{SD})$ & $\mathrm{N}$ & $\mathrm{N}(\%)$ & $M(\mathrm{SD})$ & $t$ & $\chi^{2}$ \\
\hline Age & 668 & & $76.4(4.9)$ & 194 & & $76.02(4.8)$ & .90 & \\
\hline Gender & 668 & & & 192 & & & & $10.57^{* * *}$ \\
\hline Male & & $424(63.5)$ & & & $98(50.5)$ & & & \\
\hline Female & & $244(36.5)$ & & & $96(49.5)$ & & & \\
\hline Number of Chronic Conditions & 668 & & $7.0(3.3)$ & 194 & & $8.5(3.6)$ & $5.37^{* * *}$ & \\
\hline Body Mass Index & 665 & & $27.2(4.9)$ & 194 & & $26.9(4.1)$ & 0.82 & \\
\hline MoCA Scores & 666 & & $25.9(2.5)$ & 194 & & $26.2(2.2)$ & 1.61 & \\
\hline$>26$ & & 286(2.9) & & & 91(46.9) & & & \\
\hline$<26$ & & $380(57.1)$ & & & 103(53.1) & & & \\
\hline \multicolumn{9}{|l|}{ Medication Use } \\
\hline Anticholinergics & 668 & & & 192 & & & & $4.23 *$ \\
\hline Yes & & $7(1.0)$ & & & $6(3.1)$ & & & \\
\hline No & & $661(99.0)$ & & & $188(96.9)$ & & & \\
\hline Benzodiazepines & 668 & & & 192 & & & & $32.62^{* * *}$ \\
\hline Yes & & $43(6.4)$ & & & $39(20.1)$ & & & \\
\hline No & & $625(93.6)$ & & & $155(79.7)$ & & & \\
\hline Geriatric Depression Scale (GDS) & 668 & & & 194 & & & & $5.99^{*}$ \\
\hline GDS Score $\leq 5$ & & $659(98.7)$ & & & $186(95.9)$ & & & \\
\hline GDS Score $>5$ & & $9(1.3)$ & & & $8(4.1)$ & & & \\
\hline SDF & 656 & & $35.57(7.47)$ & 190 & & $33.80(7.08)$ & $2.90 * *$ & \\
\hline SDA & 657 & & $5.26(4.11)$ & 191 & & $5.71(4.15)$ & 1.33 & \\
\hline SDA & 657 & & $36.34(6.01)$ & 191 & & $34.21(6.27)$ & $4.26 * * *$ & \\
\hline
\end{tabular}




\section{ACKNOWLEDGMENTS}

The Candrive II prospective cohort study of older drivers is supported by the Canadian Institutes for Health Research.

\section{REFERENCES}

Barrash J., Stillman A., Anderson, S. W., Uc, E. Y., Dawson, J. D., \& Rizzo, M. (2010). Prediction of driving ability with neuropsychological tests: demographic adjustments diminish accuracy. Journal of the International Neuropsychological Society, 16(4), 679686.

Bjorngaard, J. H., Bjerkeset, O., Romundstad, P., \& Gunnell, D. (2011). Sleeping problems and suicide in 75,000 norwegian adults: A 20 year follow-up of the HUNT I study. Sleep, 34(9), 1155-1159.

Blanchard, R. A., \& Myers, A. M. (2010). Examination of driving comfort and self-regulatory practices in older adults using in-vehicle devices to assess natural driving patterns. Accident Analysis \& Prevention, 42, 1213-1219.

Chen, Q., Hayman, L. L., Shmerling, R. H., Bean, J. F., \& Leveille, S. G. (2011). Characteristics of chronic pain associated with sleep difficulty in older adults: The maintenance of balance, independent living, intellect, and zest in the elderly (MOBILIZE) Boston study. Journal of the American Geriatrics Society, 59(8), 1385-1392.

Ellen, R. L., Marshall, S. C., Palayew, M., Molnar, F. J., Wilson, K. G., \& Man-Son-Hing, M. (2006). Systematic review of motor vehicle crash risk in persons with sleep apnea. Journal of Clinical Sleep Medicine, 2(2), 193-200.

Foley, D. J., Monjan, A. A., Brown, S. L., Simonsick, E. M., Wallace, R. B., \& Blazer, D. G. (1995). Sleep complaints among elderly persons: An epidemiologic study of three communities. Sleep, 18(6), 425-432.

Leproust, S., Lagarde, E., \& Salmi, L. R. (2008). Systematic screening for unsafe driving due to medical conditions: Still debatable. BMC Public Health, 8, 27.

Lopez-Torres Hidalgo, J., Navarro Bravo, B., Parraga Martinez, I., Andres Pretel, F., Tellez Lapeira, J., \& Boix Gras, C. (2011). Understanding insomnia in older adults. International Journal of Geriatric Psychiatry, 27, 1086-1093.

MacDonald LM, Myers AM, Blanchard RA. (2008). Correspondence among olderbdrivers’ perceptions, abilities, and behaviors. Topics in Geriatric Rehabilitation, 24, 239-52.

Ohayon, M. M. (2002). Epidemiology of insomnia: What we know and what we still need to learn. Sleep Medicine Reviews, 6(2), 97-111. doi: 10.1053/smrv.2002.0186

Philip, P., Sagaspe, P., Moore, N., Taillard, J., Charles, A., Guilleminault, C., \& Bioulac, B. (2005). Fatigue, sleep restriction and driving performance. Accident; Analysis and Prevention, 37(3), 473-478.

Sagaspe, P., Taillard, J., Bayon, V., Lagarde, E., Moore, N., Boussuge, J., Philip, P. (2010). Sleepiness, near-misses and driving accidents among a representative population of french drivers. Journal of Sleep Research, 19(4), 578-584 
Vanlaar, W., Simpson, H., Mayhew, D., \& Robertson, R. (2008). Fatigued and drowsy driving: A survey of attitudes, opinions and behaviors. Journal of Safety Research, 39(3), 303-309.

Vaz Fragoso, C. A., Araujo, K. L. B., Van Ness, P. H., \& Marottoli, R. A. (2008). Prevalence of sleep disturbances in a cohort of older drivers. The Journals of Gerontology: Series A: Biological Sciences and Medical Sciences, 63A(7), 715-723.

Verster, J. C., Veldhuijzen, D. S., \& Volkerts, E. R. (2004). Residual effects of sleep medication on driving ability. Sleep Medical Review, 892 (4), 309-325.

Sleep in America poll. (2012). Retrieved from www.sleepfoundation.org.

Vitiello, M. V. (1997). Sleep disorders and aging: Understanding the causes. The Journals of Gerontology.Series A, Biological Sciences and Medical Sciences, 52(4), M189-91. 